\title{
E-PELLET - CARVÃO VEGETAL COMO ALTERNATIVA ENERGÉTICA PARA PELOTIZAÇÃO*
}

\author{
Davi Silva Braga ${ }^{1}$ \\ Lucas Gabriel Rabelo Criscuolo² \\ José Luiz Ramos Carvalho
}

\begin{abstract}
Resumo
O processo de produção das pelotas é intensivo em consumo energético, tanto em energia térmica como energia elétrica. Considerando apenas o custo de transformação de minério de ferro para pelota, a energia térmica se torna o maior custo na produção destas e, por isso, encontrar fontes alternativas, combustíveis mais acessíveis e aumentar a eficiência energética, tornam-se objetivos claros na definição das metas de trabalho dos produtores de pelotas de minério de ferro. O objetivo, aqui, foi apresentar a alternativa encontrada na Usina de Pelotização de Jeceaba para substituição de gás natural por carvão vegetal pulverizado. Foram empregados equipamentos adquiridos para moagem e injeção de carvão mineral, que foram adaptados e integrados em uma Usina já existente de forma a aproveitar a oferta interna de moinha de carvão vegetal. Após seis meses de implantação, foi atingida taxa de substituição média de $53 \%$ no queimador principal, e a mesma proporção na redução das emissões de $\mathrm{CO}_{2}$ de origem fóssil.
\end{abstract}

Palavras-chave: Pelotização; carvão vegetal; energia térmica.

\section{E-PELLET - CHARCOAL AS AN ENERGY ALTERNATIVE FOR PELOTIZATION Abstract}

The production process of the pellets is intensive in energy consumption, as in thermal energy as in electric energy. Considering only the cost of transforming iron ore into pellets, thermal energy becomes the major cost for producing pellets, and therefore finding alternative sources, more accessible fuels and increasing energy efficiency, become clear goals in defining Targets for iron ore pellet producers. The objective here was to present the alternative found at the Jeceaba Pelletizing Plant for the replacement of natural gas with pulverized charcoal. Equipment purchased for grinding and injection of mineral coal was used, which were adapted and integrated into an existing plant in order to take advantage of the internal supply of charcoal fines. After six months of implementation, the average substitution rate of $53 \%$ in the main burner was reached, and the same proportion in the reduction of $\mathrm{CO}_{2}$ emissions of fossil origin.

Keywords: Pelletizing; charcoal; thermal energy.

1 Bacharel em Engenharia Química - UFMG, Engenheiro de Processos, Pelotização, Vallourec Soluções Tubulares do Brasil, Jeceaba, Minas Gerais, Brasil.

2 Bacharel em Engenharia de Controle e Automação - UFMG, Engenheiro de Processos, Pelotização, Vallourec Soluções Tubulares do Brasil, Jeceaba, Minas Gerais, Brasil.

3 Pós Graduado em Engenharia Metalúrgica - UFMG, Consultor Vallourec, JLR Engenharia \& Consultoria. 


\section{INTRODUÇÃO}

O processo de produção das pelotas é intensivo em consumo energético, principalmente energia térmica de combustíveis. MEYER [1] divide este processo de produção em três etapas: preparação da matéria prima, formação das pelotas verdes e queima das pelotas. As duas primeiras etapas são mais intensivas em consumo de energia elétrica, pois normalmente empregam correias transportadoras, moinhos, prensa de rolos, espessadores, misturadores e discos ou tambores de pelotização. Já o consumo intensivo de energia térmica ocorre na etapa de queima das pelotas, na qual se praticam temperaturas de queima de cerca de $1400^{\circ} \mathrm{C}$.

\subsection{Fontes de Energia térmica}

Para se alcançar as temperaturas necessárias ao processo de tratamento térmico da pelota se utilizam normalmente carvão mineral, óleos combustíveis e gás natural; também foram feitos experimentos com carvão vegetal como descrito em [5],[6] e [7]. O gás natural representava em 2014, segundo TAETS [2], $12 \%$ da matriz energética brasileira e tem apresentado sucessivo crescimento, com a participação deste na matriz energética nacional atingindo o patamar de 13,7\% em 2015, segundo dados do Balanço Energético Nacional 2016 [3], com a demanda industrial por gás natural registrando uma expansão de $2,5 \%$ em relação ao ano anterior, com destaque para o setor de ferro gusa e aço (18,1\%). A utilização do gás natural em processos industriais traz, de acordo com TAETS [2], benefícios operacionais e ambientais, destacando-se: redução de custos de operação/manutenção, e redução de emissões atmosféricas, especialmente $\mathrm{CO}_{2}$ em relação aos óleos combustíveis e carvão mineral. Mas, o gás natural figura entre as fontes de energia fóssil.

\subsection{Carvão Vegetal como alternativa renovável}

O carvão vegetal figura como uma alternativa renovável, mas cerca de $50 \%$ deste, no Brasil, é produzido a partir de florestas nativas, conforme citado por SCARPINELLA[9]. O corte de floresta nativa, tal qual o carvão fóssil extraído, leva o carbono da Terra que é liberado para a atmosfera no final. Por outro lado, conforme FERREIRA[4] e MATHIESON[10], o uso de carvão vegetal a partir de florestas plantadas pode ser considerado neutro, uma vez que as árvores em crescimento absorvem uma quantidade de $\mathrm{CO}_{2}$ que compensa o que é liberado pela queima do carvão, mesmo considerando a necessidade de uso de energia na gestão de plantações, colheita, processamento (pirólise) e transporte, a avaliação do ciclo de vida mostra que essa consideração é válida ou mesmo conservadora.

CAETANO [5] e CARIGNANI [6] relatam experiências da antiga Cia Vale do Rio Doce, com sucesso na utilização de carvão vegetal misturado ao minério que compõe as pelotas, bem como combustível auxiliar em substituição ao óleo combustível. As pelotas produzidas por estes foram validadas nos testes de qualidade em suas usinas produtoras, bem como em laboratório internacional na Europa. O que impediu o uso continuado do carvão vegetal foi a indisponibilidade de fontes confiáveis e contínuas de fornecimento. A SAMARCO [7] também realizou avaliação da utilização de carvão vegetal, porém como combustível interno nas pelotas. Os resultados indicaram bom potencial de aproveitamento com qualidade próxima ao carvão mineral e teores de Ferro mais elevados nas pelotas. 


\subsection{Motivação e Objetivo}

Pelo alto custo da energia térmica na produção pelotas, encontrar fontes alternativas, combustíveis mais acessíveis e aumentar a eficiência energética, tornam-se objetivos claros na definição das metas dos produtores de pelotas de minério de ferro.

O objetivo, deste trabalho, é apresentar a alternativa encontrada na Usina de Pelotização de Jeceaba para substituição de gás natural por carvão vegetal pulverizado no queimador principal e também como aditivo misturado ao minério pellet feed na receita da pelota.

\section{MATERIAIS E MÉTODOS}

Os experimentos deste trabalho foram executados na Pelotização da Vallourec Soluções Tubulares do Brasil, subsidiária do Grupo Francês Vallourec, na Usina Siderúrgica Integrada de Jeceaba. Com capacidade para 1,36 milhões de toneladas de pelota por ano, pelotamento por 05 discos de $6 \mathrm{~m}$ de diâmetro e tratamento térmico Grate-Kiln, conforme detalhado na figura 1.

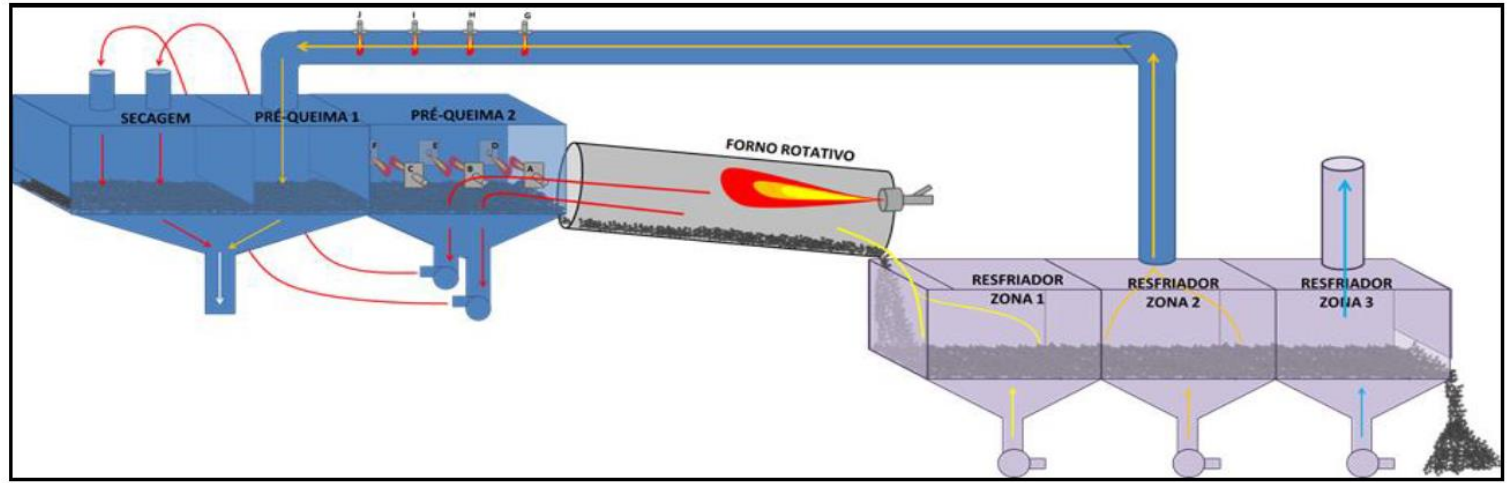

Figura 1. Modelo esquemático do forno Grate-Kiln na Usina da Vallourec [8].

\subsection{Descritivo do Processo Grate-Kiln}

O forno grelha é composto por três zonas. A primeira delas, a secagem, é responsável pela retirada da água contida nas pelotas verdes através da evaporação a $100^{\circ} \mathrm{C}$. Em seguida, tem-se a pré-queima 1 e a pré-queima 2, que possui queimadores auxiliares a fim de aumentar o aporte térmico dessa zona e iniciar a calcinação dos carbonatos e queima de combustíveis internos. Já o forno rotativo é o principal fornecedor de energia do sistema, promovendo o tratamento térmico das pelotas com a utilização de queimador axial de alta potência, alimentado a gás natural e/ou carvão pulverizado, garantindo resistência mecânica às pelotas. Em relação aos outros fornos comumente utilizados, a queima em fornos rotativos é mais homogênea, por promover troca térmica pelos mecanismos de condução por contato com o refratário aquecido, convecção com ar quente e radiação direta da chama. As pelotas produzidas possuem melhores índices de abrasão devido ao processo de tamboreamento provocado pela rotação do forno. O resfriador circular, constituído por três zonas, tem como objetivo retirar o máximo de calor das pelotas, reaproveitando-o nas etapas de secagem e aquecimento. 


\subsection{Nova instalação para injeção de Carvão Vegetal}

No projeto original desta Usina, fornecido pela BSIET (Beijing Shougang Institute of Engineering Technology), estava inclusa uma unidade para receber, estocar, moer, e injetar carvão mineral no queimador principal do forno rotativo. Mas, por questões de custo de implantação, dificuldades na obtenção e armazenagem de carvão mineral, foi definido que o startup do processo, em 2013, seria com gás natural e os equipamentos para combustível sólido permaneceriam em estoque para avaliação de viabilidade futura. Em 2016, tendo em vista a crise financeira no Brasil, e acirramento das ações de redução de custos nos produtores e clientes de pelotas, foi reavaliada a possibilidade de consumo de combustíveis sólidos, com a viabilidade econômica favorável ao carvão vegetal. Este combustível já é produzido pelo Grupo Vallourec em sua base florestal renovável e possibilitou a tomada de decisão para o investimento, no qual foram empregados, adaptados e montados os equipamentos adquiridos para moagem e injeção de carvão mineral, integrando na Usina já existente de forma a aproveitar a oferta interna de moinha de carvão excedente do peneiramento do carvão vegetal nos Altos-fornos da Vallourec Soluções Tubulares, bem como disponibilidade de moinho pendular para cominuição da moinha atingindo a faixa granulométrica de $80 \%$ passante em $0,074 \mathrm{~mm}$.

A instalação inclui, conforme diagrama esquemático apresentado na Figura 2, bocal para conexão com caminhão tanque pressurizado, tubulação para transporte, silo de armazenamento do carvão pulverizado, alimentador dosador rotativo, compressores para gerar o ar de transporte, filtro de mangas para despoeiramento e tubulação de injeção no queimador do forno rotativo de queima de pelotas.

As tubulações de entrada do silo e de injeção são dotadas de aceleradores por ar comprimido, ponto de amostragem, válvulas de alívio, válvulas on-off com sensor de abertura, curvas de raio longo com proteção por caixa de concreto e compensação eletrostática. O silo de $60 \mathrm{~m}^{3}$ permite estocar até 20 ton de carvão pulverizado, sendo dotado de vários sistemas de segurança contra incêndio: termopares ao longo do corpo, detecção de gás $\mathrm{CO}$, fluidização e inertização por nitrogênio, filtro de mangas com válvula duplo pêndulo e alívio de pressão.

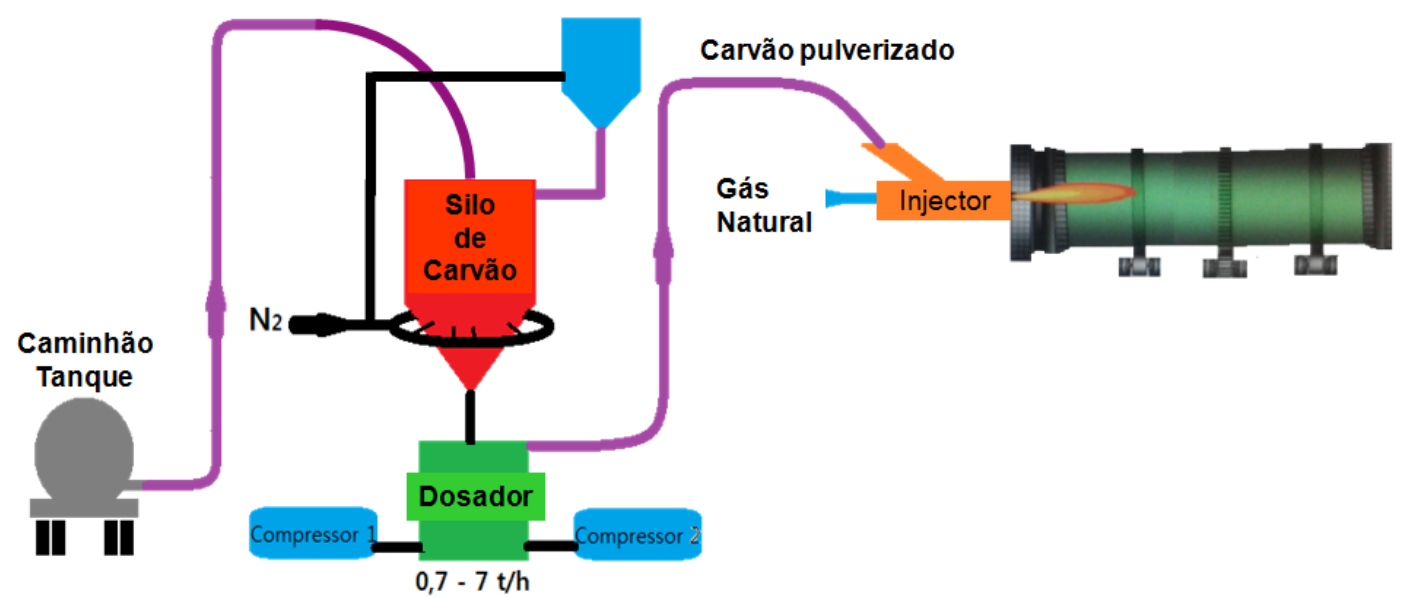

Figura 2. Diagrama esquemático da nova instalação para injeção de carvão pulverizado. 


\subsection{Análise de gases}

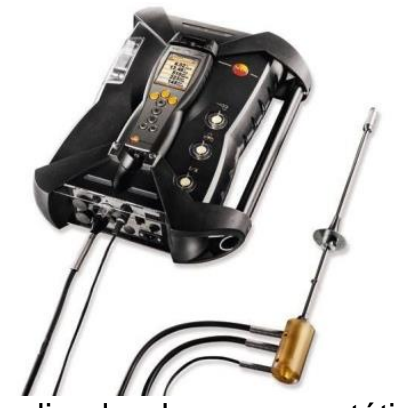

Figura 3. Analisador de gases portátil Testo 350.

Como ferramental para este trabalho, antes, durante a transição de combustíveis e no controle de rotina, foi utilizado o analisador portátil Testo 350, figura 3, para avaliar as emissões do processo de queima. Trata-se de um analisador que atende as altas exigências dos processos industriais, podendo ser operado com até 6 sensores de gás, para medição de $\mathrm{CO}$, NO, NO2, SO2, H2S, CxHy e CO2.

\section{RESULTADOS E DISCUSSÃO}

Foi concluída em Dez/2016 a montagem e comissionamento do sistema de injeção de combustível sólido e em Jan/2017, realizado o primeiro teste de injeção de carvão vegetal, conforme figura 3. A operação contínua iniciou-se no mesmo mês.

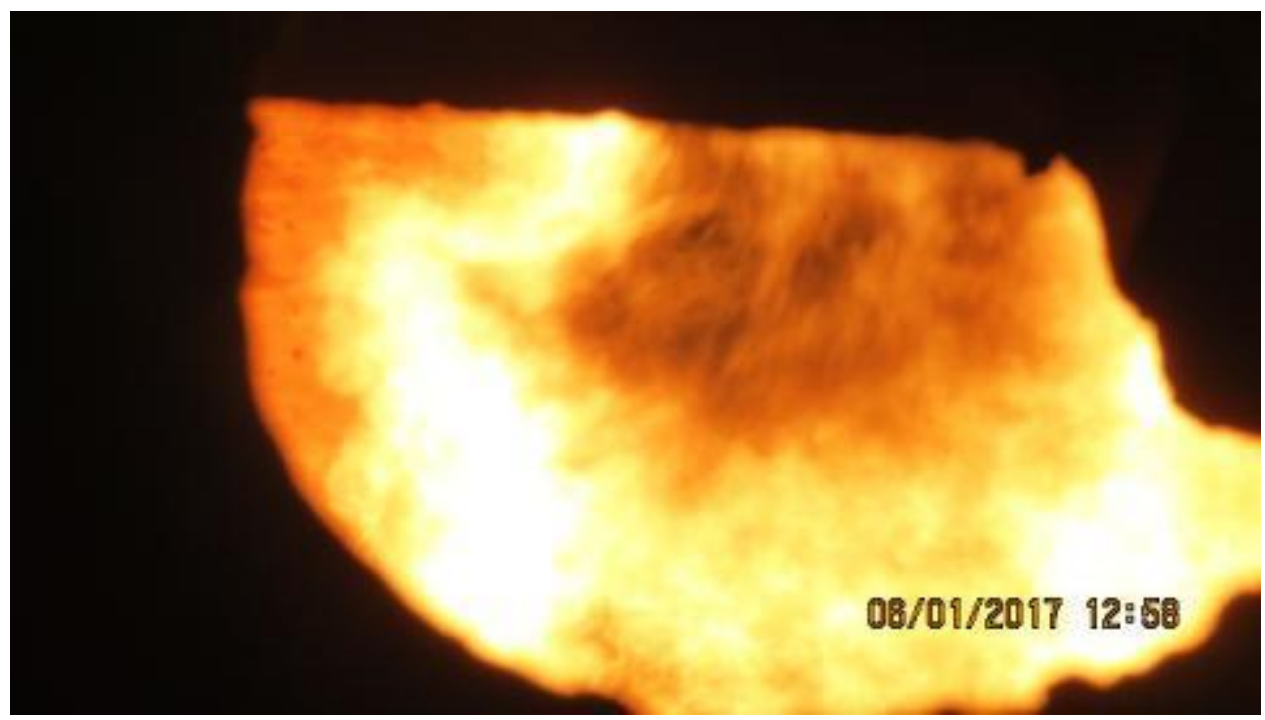

Figura 3. $1^{\circ}$ Teste de queima na chama do forno rotativo com carvão vegetal pulverizado.

Mantendo-se a mesma faixa de energia injetada, através do queimador do forno rotativo, verificou-se que a substituição de gás natural por carvão vegetal se mostrou viável nos últimos seis meses de operação, mantendo ou ainda melhorando a qualidade física da pelota, principalmente em resistência compressão, conforme resultados apresentados na Tabela 1. 
Tabela 1. Comparativo Energia térmica e qualidade da pelota*

\begin{tabular}{|c|c|c|c|c|c|}
\hline \multirow{2}{*}{ Período } & \multicolumn{3}{|c|}{ Energia térmica injetada (Mcal/tp) ${ }^{* *}$} & \multirow{2}{*}{$\begin{array}{c}\text { Taxa de } \\
\text { substituição } \\
\text { média }\end{array}$} & \multirow{2}{*}{$\begin{array}{c}\text { Compressão } \\
\text { Pelota } \\
\text { (daN/p) }\end{array}$} \\
\hline & Gás natural & Carvão Vegetal & Total & & \\
\hline Out - Dez 2016 & 245 & 0 & 245 & $0 \%$ & 319 \\
\hline Jan - Mai 2017 & 115 & 127 & 242 & $53 \%$ & 338 \\
\hline
\end{tabular}

O aumento na resistência da compressão implica, em primeira analise, maior capacidade de queima de pelotas no forno rotativo e consequentemente possibilidade de aumento da capacidade produtiva caso a restrição de produção estivesse no processo de queima de pelotas. Esse aumento da capacidade de queima no forno rotativo, por outro lado, reduz a capacidade de fornecer calor para o forno grelha, sendo necessário tomar algumas medidas como utilização dos queimadores auxiliares do forno grelha que são utilizadas para garantir a etapa de secagem e pré queima das pelotas. Estes queimadores auxiliares são alimentados por gás natural, mas este consumo adicional está contabilizado na parcela de gás natural que ainda foi mantida após o início do processo de substituição global.

\subsection{Emissões de $\mathrm{CO}_{2}$ e teor de umidade dos gases combustos}

Como resultado da substituição do carvão vegetal no processo de combustão verificou-se alterações na composição dos gases combustos do tratamento térmico conforme os cálculos apresentados na Tabela 2.

Tabela 2. Comparativo das emissões de $\mathrm{CO}_{2}$ e $\mathrm{H}_{2} \mathrm{O}$ nos fumos de combustão

\begin{tabular}{ccccc}
\hline Período & Combustíveis & $\begin{array}{c}\text { Emissão de } \mathrm{CO}_{2} \\
\mathbf{k g} / \mathbf{t p}\end{array}$ & $\begin{array}{c}\text { Teor de } \mathrm{H}_{2} \mathrm{O} \\
\mathbf{k g} / \mathbf{t p}\end{array}$ & Fonte \\
\hline Out - Dez 2016 & Gás Natural & 83,3 & 63,1 & Fóssil \\
\hline \multirow{3}{*}{ Jan - Mai 2017} & Gás Natural & 39,1 & 29,6 & Fóssil \\
\cline { 2 - 5 } & Carvão Vegetal & 55,9 & 4,6 & Renovável \\
\cline { 2 - 5 } & TOTAL & 95,0 & 34,2 & Mista \\
\hline
\end{tabular}

Além disso, foi confirmado aumento de ordem de $15 \%$ na emissão total de $\mathrm{CO}_{2}$ através de medições realizadas em campo, com o instrumento analisador portátil descrito na seção anterior. Os resultados obtidos em percentual de $\mathrm{CO}_{2}$ na mistura de ar e gás combusto são da ordem de 2 a $3 \%$.

No entanto a fonte de aumento da geração de $\mathrm{CO}_{2}$ é um combustível renovável e conforme explanado na Introdução, este impacto não contribui para o aumento global da emissão de $\mathrm{CO}_{2}$, resultando assim em redução de $53 \%$ na emissão de $\mathrm{CO}_{2}$ de origem fóssil, apresentado na Tabela 3.

Tabela 3. Redução de $\mathrm{CO}_{2}$ não renovável e de $\mathrm{H}_{2} \mathrm{O}$ nos gases combustos

\begin{tabular}{ccc}
\hline Período & Emissão de $\mathbf{C O}_{2}$ & Teor de $\mathbf{H}_{2} \mathbf{O}$ \\
\hline Jan - Mai 2017 & & \\
em relação à & $-53 \%$ & $-46 \%$ \\
Out - Dez 2016 & & \\
\hline
\end{tabular}


Para o processo de pelotização grate-kiln, a etapa de secagem das pelotas tem um papel chave, pois as pelotas precisam alcançar nível de resistência à compressão suficiente para garantir que estas sobrevivam à transferência do forno grelha para o forno rotativo.

Foi observado nos cálculos de combustíveis e emissões, que o teor de umidade gerado na combustão do carvão vegetal é $46 \%$ menor que no período avaliado somente com gás natural, conforme a Tabela 3. A secagem das pelotas, como descrito por MEYER[1] se processa em três etapas envolvendo a secagem da umidade superficial, a difusão da água nos poros para a superfície por capilaridade e a remoção da água de hidratação do minério e aditivos. A umidade precisa chegar à superfície da pelota e transferir-se para o ar circundante aumentando sua pressão parcial de água. Essa transferência de massa se processará de acordo com propriedades do gás de secagem, que apresentando menor teor de umidade, neste caso, promoverá maior gradiente de pressão parcial de água aumentando taxa de transferência desta da pelota para a fase gás. Na prática, o efeito aqui descrito de melhoria da taxa de secagem foi observado através do aumento nas temperaturas médias das primeiras caixas de vento do forno grelha comparando-se períodos com e sem utilização de carvão vegetal, como pode ser visto no gráfico da Figura 4.

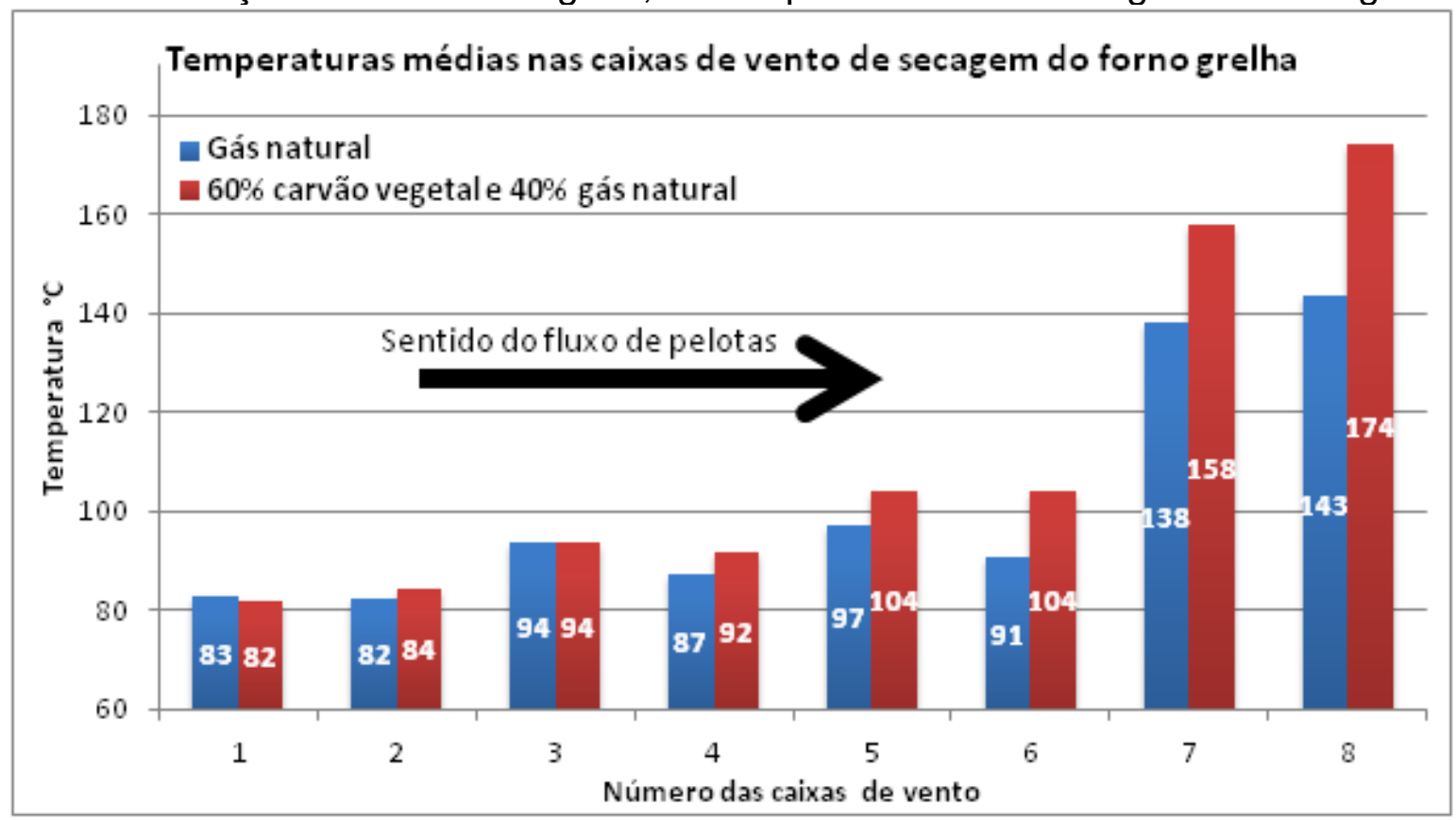

Figura 4. Temperatura das caixas vento na etapa de secagem das pelotas.

\subsection{Matriz energética e novos desafios}

Além do combustível nos queimadores, a usina utiliza coque verde de petróleo e coprodutos do alto forno (lama e pó do sistema de lavagem de gases) como fonte de combustível interno no processo de queima. As análises imediata e completa destes coprodutos apontam que cerca de $50 \%$ em massa são finos de carvão vegetal, contribuindo para reduzir a energia externa adicionada ao processo.

A figura 5 mostra a matriz de distribuição de consumo de energia térmica na usina após a instalação do sistema de injeção de carvão. 


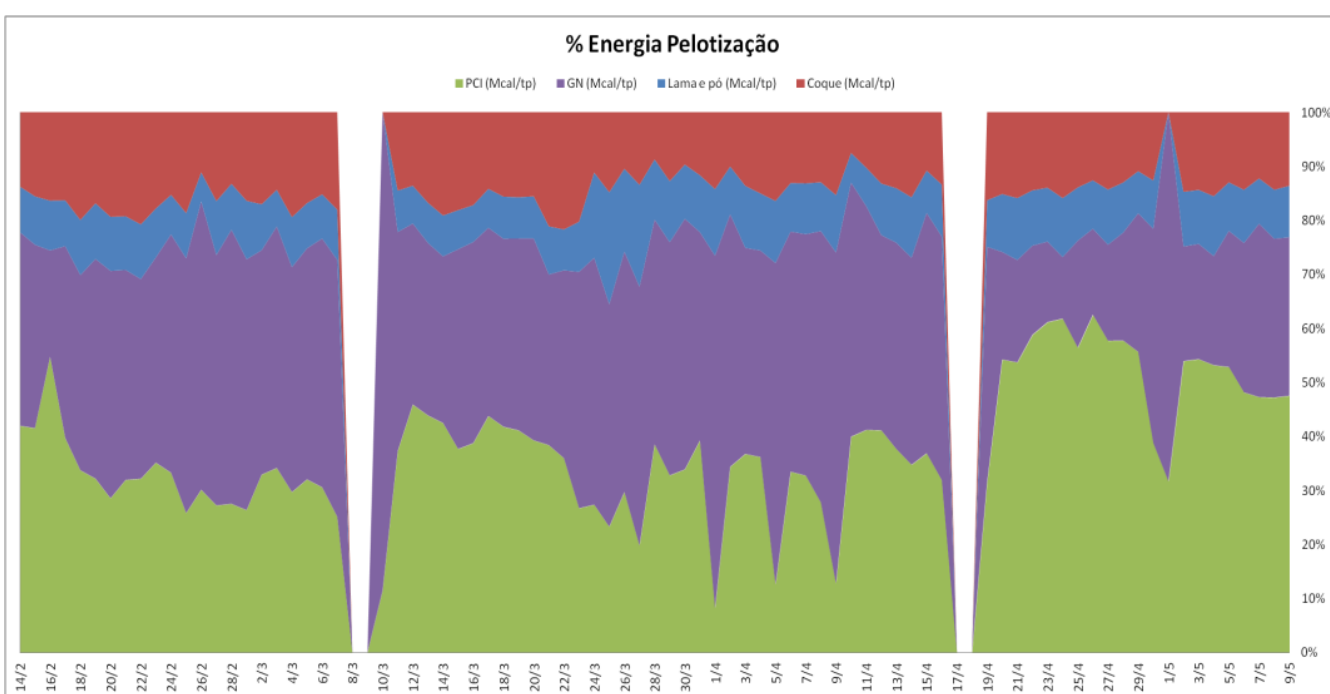

Figura 5. Evolução diária da matriz energética após o startup da injeção de carvão vegetal.

Os desafios associados ao emprego do carvão vegetal no processo de queima das pelotas incluem a presença de cinzas no carvão e a maior temperatura de chama que podem provocar aumento na formação de colagem na superfície interna do forno rotativo sobre a camada refratária. Um maior controle de processo é exigido para manter a estabilidade operacional.

Além disso, melhorias preventivas estão sendo realizadas com relação à aplicação de refratários nos fornos com tecnologia tipo "Sol-Gel" da RHI-AG para maior resistência ao ataque por álcalis $\left(\mathrm{Na}_{2} \mathrm{O}\right.$ e $\left.\mathrm{K}_{2} \mathrm{O}\right)$ presentes nas cinzas.

Um aspecto crítico para sucesso no emprego do Carvão vegetal é quanto à homogeneidade de qualidade do carvão pulverizado. Umidade, teor de cinzas, carbono fixo, conteúdo energético (Mcal/kg) e distribuição granulométrica são as principais variáveis acompanhadas e controladas no processo de cominuição da moinha de carvão vegetal e fornecimento do carvão pulverizado para injeção.

É importante ressaltar também os benefícios de obter o carvão de produção própria nas Unidades Florestais da Vallourec. Nestas, contamos com desenvolvimento de clones de eucalipto para maior rendimento e estabilidade da madeira, carbonização em fornos com carregamento e descarga mecanizados, recuperação de alcatrão e outros condensáveis nos fornos sendo utilizados em reciclagem de energia no processo de carbonização e vendidos como coprodutos, evitando emissões de gases de efeito estufa.

Este trabalho de substituição de combustíveis tem sido um grande desafio para a equipe de Operação e Manutenção da usina de Pelotização da Vallourec, em parte pelo pioneirismo do emprego do carvão vegetal pulverizado em Pelotização de Minério de ferro pelo processo Grate-kiln, do qual não encontramos aplicação anterior em outras usinas na literatura de referência.

Mas é fato que os benefícios e oportunidades advindos têm superado as dificuldades e os desafios, mantendo o interesse da Vallourec Soluções Tubulares do Brasil em continuar o trabalho buscando sempre a melhoria contínua no desenvolvimento e produção de pelotas mais ambientalmente correta que denominamos E-Pellet. 


\section{CONCLUSÃO}

O emprego do carvão vegetal tem cumprido o objetivo de ser uma fonte energética alternativa e renovável e de menor custo frente ao gás natural mais intensivo em custos e de origem fóssil.

Os equipamentos empregados mostraram capacidade e disponibilidade para manter os níveis térmicos necessários e a taxa de energia injetada através do queimador do forno rotativo com sucesso nos últimos seis meses de operação, mantendo ou ainda melhorando a qualidade física da pelota.

Os cálculos e medições realizadas indicaram aumento da geração total de $\mathrm{CO}_{2}$, mas houve redução de $53 \%$ na emissão de $\mathrm{CO}_{2}$ de origem fóssil, permitindo assim avaliar que 0 trabalho contribui com as metas nacionais em busca de fontes energéticas mais sustentáveis e renováveis.

Como impactos na rotina operacional, verificamos melhoria na secagem de pelotas e aumento na geração de colagem de materiais na superfície interna do forno rotativo.

A Vallourec Soluções Tubulares buscará continuar o trabalho de substituição de combustíveis de origem renovável objetivando atingir $100 \%$ de substituição no queimador principal e futuramente nos queimadores auxiliares, bem como substituição do coque de petróleo por coprodutos da Siderurgia como Lama e pó de topo de alto forno e carepa de aço, de modo evoluir em sustentabilidade.

\section{REFERÊNCIAS}

1 MEYER K. Pelletizing of Iron Ores. Spring-Verlag, Berlim Heidelberg, New York, 1980

2 TAETS LAR. Análise da participação do gás natural na matriz energética e a aplicação desse combustível no processo de pelotização de minério de ferro, Dissertação (Mestrado em Conversão de Energia) - Instituto Engenharia Mecânica, UNIFEI. 2014.

3 EMPRESA DE PESQUISA ENERGÉTICA. BEN - Balanço Energético Nacional 2016. EPE, 2016. Acesso em 09 abr. 2017. Disponível em <https://ben.epe.gov.br/>.

4 FERREIRA OC. Emissões de Gases de Efeito Estufa na Produção e no Uso do Carvão Vegetal. Economia e Energia. 2000; $n^{\circ} 20$.

5 CAETANO AR, FERNANDES RS, QUEIROGA JMR. Programa de Redução do Consumo de Óleo Combustível nas usinas de pelotização da Cia Vale do Rio Doce. Encontro Nacional de Tratamentos de Minérios e Metalurgia Extrativa, Volume 1, 1985.

6 CARIGNANI M, BARNABA P, ARAUJO MC. Usina de pelotização Itabrasco: resultados de operação e qualidade alcançados na produção de pelotas de alta basicidade para alto-forno. Encontro Nacional Tratamentos Minérios Metalurgia Extrativa, Vol.1, 1985.

7 SAMARCO. Utilização de carvão vegetal na produção de pelotas da Samarco. Relatório Interno, Ponta Ubu, Março 2000.

8 BRAGA, DS, CRISCUOLO LGR, PORTILHO, TMM, SAMPAIO RS. Soft Sensor do Processo Grate Kiln da Pelotização da VSB. 4ํㅗㅇ Simpósio Brasileiro de Aglomeração de Minério de Ferro, ABM Week, Rio de Janeiro - RJ, 2016.

9 SCARPINELLA, CA, TAKANO C, TAGUSAGAWA SY, MOURÃO MB, LENZ GFB. Charcoal Ironmaking: A Contribution for $\mathrm{CO} 2$ Mitigation. Fray International Symposium. Metals and Materials Processing in a Clean Environment, Cancún, México, Vol.2, 2011.

10 MATHIESON JG, ROGERS H, SOMERVILLE M, RIDGEWAY P, JAHANSHAHI S. Use of Biomass in the Iron and Steel Industry. International Conference on Energy Efficiency and CO2 Reduction in Steel Industry, Dusseldorf, Germany, 2011. 